УДК 81-114/2

ББК (Ш) 81.2Фр

DOI: https://doi.org/10.17308/lic.2020.4/3084

\title{
ИНТЕГРАЦИЯ КАК ФАКТОР ДИНАМИЧНОСТИ СИСТЕМЫ ФРАНЦУЗСКОГО ЯЗЫКА
}

\author{
Н. А. Нечаева \\ Дипломатическая академия МИД Российской Федерации

\begin{abstract}
INTEGRATION AS A DYNAMIC FACTOR OF THE FRENCH LANGUAGE SYSTEM
\end{abstract}

\author{
N. A. Nechaeva \\ Diplomatic Academy of Ministry of Foreign Affairs of the Russian Federation
}

\begin{abstract}
Аннотация: в статье анализируются процессы интеграции во франиузском языке (на примере языка экономики). В основе данных процессов лежит взаимодействие и синхронная активизация разных концептов. Для понимания механизма интеграџионных процессов необходимо обращение к семантической структуре языковой единицы, представляющей собой совокупность ее лексических значений. Значение языковой единицы структурировано по по́левому принцииу, а формирующче его компоненты образуют иерархию по яркости. Динамические процессы в семантической структуре единицы - актуализация или нейтрализация - обеспечивают мобильность языковой единицы, ее возможность создавать и реализовать определенное количество смыслов в зависимости от коммуникативной задачи. В прочессе интеграции взаимодействие компонентов в определенной комбиначии позволяет создавать интегративные варианты. В результате этих процессов появляются новые смыслы, которые вербализуются определенной языковой единицей и фиксируются контекстом. Проиессы интеграции обусловлены реакциями связей в семантической структуре языковой единицы, позволяющими компонентам единицы языка взаимодействовать с другими в пределах одного языкового уровня. Основные силь, действующие в семантической структуре языковой единицы, определяются в работе как семантическое притяжение и семантическое отталкивание. Процессы языковой интеграции достаточно сложны, они проходят условно несколько этапов. Подобные проиессы могут иметь место как между компонентами внутри семантического поля языковой единицы, данный процесс обозначается как внутрипо́левая интеграция, так и между компонентами семантических полей двух и более единии, этот процесс характеризуется как межпо́левая интеграция. Суть данных прочессов заключается в постоянном стремлении компонентов к созданию такой комбинации, которая ведет к конечной семантической величине на данном историческом этапе развития языка.

Ключевые слова: интеграционные процессы, структура языковой единицы, ядро, периферийный компонент, ближняя и дальняя периферия, актуализаџия, нейтрализация, внутрипо́левая интеграция, межпо́левая интеграчия.
\end{abstract}

\begin{abstract}
French language (on the example of the language of economics). These processes are based on interaction and synchronous activation of different concepts. To understand the mechanism of integration processes, it is necessary to refer to the semantic structure of a linguistic unit, which is a combination of its lexical meanings. The value of a language unit is structured according to the field principle, and the components that form it form a hierarchy in brightness. Dynamic processes in the semantic structure of a unit-actualization or neutralization - provide the mobility of a language unit, its ability to create and realize a certain number of meanings, depending on the communicative task. In the process of integration, the interaction of components in a certain combination allows you to create integrative options. As a result of these processes, new meanings appear and are verbalized by a certain linguistic unit and fixed by context. The integration processes are determined by the reactions of relations in the semantic structure of a language unit, which allows the components of a language unit to interact with others within the same language level. The main
\end{abstract}

(C) Нечаева Н. А., 2020

Контент доступен под лицензией Creative Commons Attribution 4.0 License.

The content is available under Creative Commons Attribution 4.0 License. 
forces acting in the semantic structure of a linguistic unit are defined in the work as semantic attraction and semantic repulsion. The processes of language integration are quite complex, they go through several stages. Similar processes can take place both between components within the semantic field of a linguistic unit, this process is denoted as intra-field integration, and between components of semantic fields of two or more units, this process is characterized as inter-field integration. The essence of these processes is the constant desire of components to create such a combination that leads to the ultimate semantic value at this historical stage of language development.

Key words: integration processes, structure of the language unit, core, peripheral component, near and far periphery, actualization, neutralization, intrafield integration, interfield integration.

\section{Введение}

Деятельность человека, познающего окружающий внешний и свой внутренний мир, концептуализация и категоризация знаний, взаимосвязь конкретного и абстрактного, осознание изменений в окружающем мире и их вербализация - все эти когнитивные процессы реализуются в конкретных языковых актах, стимулируя изменения в языке, что находит отражение в появлении новых языковых единиц. Благодаря коммуникации человек оперирует ментальными структурами, стоящими за языковыми единицами, каждый раз порождая новые значения, подтверждая мысль о том, что любое творчество - это своего рода «возмущение разума».

Сознание человека позволяет дифференцировать и интегрировать явления действительности, осуществлять тем самым анализ и синтез этих явлений, проникать в их сущность. По мнению О. К. Ирисхановой $[1$, c. 46$]$, интеграция в языке представляет собой «наиболее общую фундаментальную операцию, результатом которой является создание сети, состоящей из ментальных (концептуальных) пространств, в которых разворачивается процесс создания нового значения, что обеспечивает единую базу для характеристики когнитивных процессов на всех уровнях языковой системы». Данное утверждение позволяет сделать вывод, что в основе интеграционных процессов в языке лежит синхронная активизация и взаимодействие разных концептов, а сам концепт является динамичным и системным образованием.

\section{Механизм интеграционных процессов в языке}

Каков же непосредственно механизм интеграционных процессов? Для понимания этих процессов необходимо обращение к семантической структуре языковой единицы. Семантическая структура языковой единицы как результата отражения объективной действительности - это совокупность ее лексических значений, рассмотренная с точки зрения их связей и производности, представляющая, по мнению И. А. Стернина [2, с. 64-67], упорядоченное единство всех семантических компонентов, которые реально связаны с данной звуковой оболочкой в сознании носителей языка. Значение языковой единицы структурировано по по́левому принципу, а формирующие его компоненты образуют иерархию по яркости.

В каждом значении, которое формулируется в форме дефиниции, выделяются ядро и периферия. В ядро входят все семантические компоненты, вошедшие в дефиницию каждого значения, актуальные для сознания коммуникантов в данный период развития языка. Они являются необходимыми и для мышления, и для коммуникации, служат для определения реалий, помогают в раскрытии содержания концепта и выявлении специфики его языкового содержания.

Периферию, которая делится на ближнюю и дальнюю, составляют компоненты, упорядоченные по убыванию яркости отдельных значений, они отражают признаки, которые могут быть реализованы в определенных контекстуальных условиях. Они несут некий структурированный в системе языка смысл, существование которого обусловлено имеющимися в языке лексическими или лексико-грамматическими парадигмами: определенная парадигма формирует данный смысл в системе языка, подготавливает его для лексической номинации [3, с. 70-75]. Они нужны в основном для мышления и редко вербализуются. К периферии также относятся прагматические компоненты, выражающие субъективный опыт, коннотации, различные коллективные или индивидуальные ассоциации.

Структура языковой единицы может быть представлена следующим образом (рис. 1).

Открытость и подвижность границы между ядром и периферией позволяет языковой единице в процессе интеграции или дифференциации конструировать и модулировать различные значения. По мнению авторов [4; 5], именно динамические процессы в семантической структуре единицы - перераспределение между компонентами ядра и периферии, преобразование их иерархии; изменение рангового статуса компонентов, т. е. их актуализация или нейтрализация - обеспечивают мобильность языковой единицы, ее возможность создавать и реализовать определенное количество смыслов в зависимости от коммуникативной задачи. Стимулом для перегруппировки компонентов является движение мысли человека, осуществляемое когнитивным механизмом изменения семантики. Таким образом, сложность семантической структуры языковой единицы обуслов- 

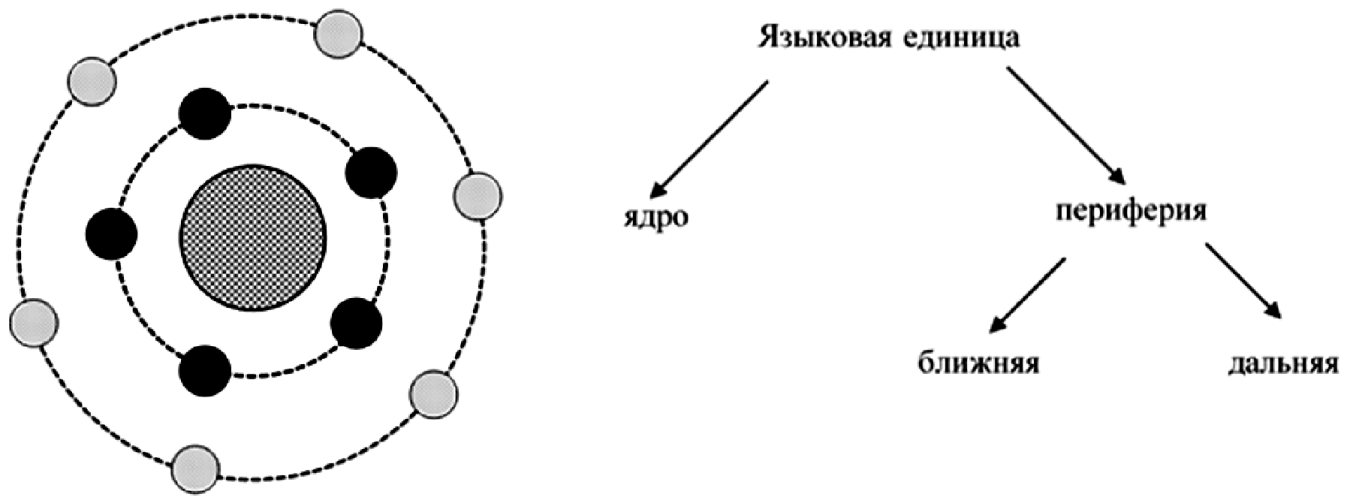

Puc. 1. Структура языковой единицы

ливает возможность развития новых значений в результате изменения в структуре значения, в соотношении составляющих его семантических компонентов [5, с. 105].

В процессе интеграции взаимодействие компонентов в определенной комбинации позволяет создавать интегративные варианты: периферийные компоненты при необходимости интегрируются в ядро, формируя новые варианты; ядерные, напротив, при интеграции в периферию могут генерировать прагматические варианты. В результате этих процессов появляются новые смыслы, которые вербализуются определенной языковой единицей и фиксируются контекстом.

Так, например, единицу bulle словари определяют как 'petite sphère remplie d'air ou de gaz qui s'élève à la surface d'un liquide en mouvement, en effervescence, en ébullition' [6], т. е. ядром данной единицы является концепт 'сфера, наполненная жидкостью или газом' Но семантика единицы bulle, как и любой языковой единицы, не ограничивается только ядром. Для понимания появления варианта 'période de forte spéculation' в примере: «...les stratégistes en investissement sont de plus en plus nombreux à s'inquiéter d'une bulle en Bourse» (Le Monde 18/10/2014) / биржевой пузырь заставляет беспокоиться все большее количество инвестиционных аналитиков / необходим учет всех компонентов. Возникновение нового варианта объясняется активизацией периферийных компонентов. Как известно, для пузыря как 'сферы, наполненной каким-то веществом', характерно расширение, вздутие. Таким образом, семантическая структура единицы bulle содержит: ядерный компонент 'сфера, наполненная жидкостью или газом' и периферийные компоненты: 'надувание', 'поднятие на поверхность'. В экономическом контексте в ментальной структуре единицы bulle, отражающей определенные ассоциации, индивидуальный и коллективный опыт, происходит перераспределение в комбинаторике ядерного и периферийных компонентов - нейтрализация ядерного компонента и интеграция периферийных компонентов в ядро, их переход в разряд ядерных, в результате чего формируется новый вариант единицы bulle как 'периода рискованных спекуляций'.

\section{Реакции связей в семантической структуре языковой единицы}

Очевидно, что процессы интеграции обусловлены реакциями связей в семантической структуре языковой единицы. Реакции связей - это силы, с которыми одни компоненты единицы языка, реализующие определенное значение, взаимодействуют с другими в пределах одного языкового уровня. Основные силы, действующие в семантической структуре языковой единицы, определяются в работе как семантическое притяжение и семантическое отталкивание. Семантическое притяжение основывается на общности одного и того же признака в разных компонентах, семантическое отталкивание - на различии признаков в компонентах. Отмечается, что эти признаки могут носить как содержательный, так и формальный характер, но безусловно, они будут характеризовать единицу уровня языка [7, с. 37].

Семантическое притяжение и семантическое отталкивание обусловлены наличием двух факторов: концептуальным характером языковой единицы и лингвистическим контекстом. Концептуальный характер языковой единицы определяется концептами, которые она объективирует. Концепт играет ключевую роль и в формировании нового смысла, и в его трансформации. В результате семантического притяжения или отталкивания изменяется семантическое или стилистическое поле языковой единицы, что может рассматриваться как проявление динамики в синхронии. При преодолении критического рубежа количественные изменения переходят в качественное изменение значения единицы [5, с. 113], и в этих случаях можно уже говорить о дифференциации, которая является другим процессом взаимодействия, связанным с интеграцией. Анализ материала показы- 
вает, что суть данных процессов заключается в постоянном стремлении компонентов к созданию такой комбинации, которая ведет к конечной семантической величине на данном историческом этапе развития языка.

\section{Формирование нового смысла в языке}

Процессы языковой интеграции достаточно сложны, они проходят условно несколько этапов.

На первом этапе происходит формирование концептов на основе действия механизма абстрагирования. Абстрагирование представляет собой процесс мысленного выделения наиболее существенных характеристик и связей типичных ситуаций. Этот процесс базируется на когнитивной способности сознания классифицировать отдельные свойства организации реального мира и создавать конкретную модель его познания. На этом этапе происходит выделение концептов ядра и периферии. Ядро концептов содержит знание основных концептуальных областей знаний и служит основой для формирования основных смысловых категорий в языке: субъект, объект, признак, процесс, количество, пространство, время и т. д. Ядерные концепты обобщают знания и отвечают за передачу языковых знаний в языке. Периферийные концепты формируют систему индивидуального видения окружающего мира, они содержат дифференцирующие признаки. Субъективная обработка информации позволяет выделить компоненты, общие для обоих концептов.

На втором этапе при действии сил притяжения/ отталкивания актуализируются/нейтрализуются смыслы ядерных концептов и компонентов периферии. При нейтрализации компонент устойчив за счет присутствия в содержании концепта наиболее общих и существенных признаков; при актуализации компонент изменчив, подвижен, подвержен переосмыслению. Ведущую роль в этих процессах играет когнитивный механизм конфигурирования, действие которого основано на способности говорящего человека к воображению. Конфигурирование - это процесс придания той или иной формы содержанию, при котором формируются новые смыслы, которые имеют пока обобщенный характер и требуют дальнейшего уточнения и конкретизации. Это позволяет предположить, что в языке динамичность концепта обусловливает различное структурирование концептуальной информации.

На третьем этапе интеграции осуществляется уточнение и конкретизация обобщенных смыслов. На данном уровне когнитивной деятельности благодаря фоновым знаниям на основе уже задействованных компонентов активизируются дополнительные элементы, которые способствуют возникновению прагматичных (оценочных) концептов. Это происходит на уровне предложения при участии дополнительных лингвистических факторов. При участии этих факторов дополнительно выделяются те или иные характеристики, в результате чего создаются различные лексико-грамматические смыслы. Именно на этом этапе происходит формирование лексической многозначности.

Таким образом, новый смысл является сочетанием нескольких концептов, которые ранее так или иначе были представлены. Некоторые концепты находят свое реальное отражение в семантической структуре языковой единицы, другие переходят в разряд «вероятных». Каждый материализованный в языковой единице концепт может проявиться в новом смысле и новом значении, при обновляемой сочетаемости единицы, при этом необходимо, чтобы сочетающаяся единица «вытащила» соответствующую долю своего значения, и сочетающиеся понятия оказались совместимыми настолько, чтобы они активизировали связанные между собой фреймы [8].

Подобное сочетание может иметь место как между компонентами внутри семантического поля языковой единицы, данный процесс обозначается как внутрипо́левая интегращуия, так и между компонентами семантических полей двух и более единиц, этот процесс характеризуется как межпо́левая интеграция.

\section{Внутрипо́левая интеграция в языке}

В процессе внутрипо́левой интеграции конструирование значения происходит за счет реакции внутренних связей между компонентами одной языковой единицы, что предполагает создание интегративных вариантов и установление между ними взаимодействия. Анализ фактического материала показал, что в процессе внутрипо́левой интеграции наблюдается несколько типов реактивного взаимодействия.

\section{1. Периферийнье компонентьл $\rightarrow$ ядро}

В семантической структуре слова сохраняется ядерный компонент; периферийные компоненты нейтрализуются и интегрируют в ядерный. Так, например, единица déficit имеет ядерный компонент 'déséquilibre entre recettes et dépenses' (превышение расходов бюджета над его доходами), что отражено в специальных словарях. Позже в семантической структуре происходят изменения: наблюдается нейтрализация компонентов 'денежные средства', 'доход', 'расход’ при сохранении концепта déséquilibre ‘несбалансированность' и притяжение периферийного компонента, который может иметь разнообразные смыслы.

Значение слова, таким образом, расширяется: в языке наряду с ядерным концептом функционирует новый вариант: déficit 'недостаточность, отсутствие' (= insuffisance, manque). Результатом такой реакции является создание новых понятий, например: déficit 
+ confiance déficit de confiance. Данный процесс может свидетельствовать о миграции языковых единиц из специальной сферы в общеупотребительную. Возможен переход из одной специальной области в другую, например, из экономической в медицинскую, политическую, социальную и т. д.: при интеграции дополнительного потенциального компонента 'медицина, лечение' в современном языке появился новый вариант - déficit immunitaire; при притяжении дополнительного периферийного компонента 'политика' - déficit démocratique. Таким образом, семантика языковой единицы эволюционирует - от значения 'несбалансированности бюджета' до 'демократического дефицита' / 'иммунного дефицита'.

\section{2. Ядро $\rightarrow$ периферийный компонент}

В семантической структуре слова ядерный компонент нейтрализуется и интегрирует в периферийный. Слово bourse с ядерным компонентом в момент своего появления в XIII в. обозначает 'sac destiné à recevoir de l'argent' ('кошелек'). В XVII в. при дальнейшем процессе интеграции периферийных компонентов marché ‘рынок', acheteur ‘покупатель', vendeur 'продавец' нейтрализуется ядерный компонент 'кошелек', в результате чего появляются несколько новых смыслов - 'деньги', 'финансовая доля', 'биржа' как место или здание, где собираются торговые люди, 'заключение сделок', 'организованный рынок ценных бумаг', которые фиксируются уже в специальных словарях. Таким образом, меняется ядерный компонент, что свидетельствует о трансформации (расширении) смысла слова. Результатом данного процесса является изменение статуса единицы, она может, например, из общеупотребительной сферы перемещаться в специальную.

\section{3. Прагматический компонент $\rightarrow$ ядро}

В семантической структуре единицы имеет место интеграция в ядро прагматических компонентов. В этом случае единица меняет свою оценочность при сохранении ядра. Рассмотрим изменение семантики единицы assainissement 'оздоровление'. В соответствии со словарной дефиницией эта языковая единица реализует «положительное» значение, характеризуя нечто как 'усиление, повышение, улучшение, например, иммунитета, работоспособности, качества жизни'. Статья в словаре верно отражает значение в понятийном плане, однако недостаточно адекватно - в плане прагматическом. Например, в экономическом контексте оценочность меняется, значение рассматриваемой единицы assainissement определяется как rigueur 'политика жесткой экономии', т. е. речь идет о периоде экономического кризиса, депрессии, что, естественного, не является позитивным:

(1) Le candidat compte économiser principalement sur la masse salariale de l'État et sur les dotations aux collectivités locales. Il situe son effort d'assainissement budgétaire entre celui des Républicains et celui du PS (Le Figaro 16/02/2017) / Кандидат рассчитывает сэкономить, главным образом, на государственном расходе на заработную плату и на дотациях местным властям. Он прилагает усилия по оздоровлению бюджета, стараясь уравновесить республиканцев и социалистов.

В примере (1) отрицательная модальность значения единицы assainissement budgétaire подтверждается выражением économiser principalement sur la masse salariale de l'État 'экономить на зарплате'.

\section{4. Два периферийных компонента $\rightarrow$ ядро}

На периферии фиксируется наличие пары антонимичных компонентов. При их интеграции в ядро у единицы появляется два антонимичных варианта. Так, в единице louage при актуализации периферийного компонента 'принимать' формируется вариант 'наем', а при интеграции компонента с противоположным значением 'отдавать' формируется вариант 'сдача внаем'. Появившиеся таким образом антонимичные значения немногочисленны в языке экономики.

\section{5. Ядро $\rightarrow$ периферийные компоненты}

В семантической структуре единицы имеет место множественная интеграция: ядерный компонент взаимодействует с несколькими периферийными, при этом последние формируют свое ядро и образуют единицу вторичной номинации. Происходит изменение функции языковой единицы, которое влияет на ее семантическое развитие, выходя за пределы собственной структуры (переосмысление значения, метафора, метонимия). Рассмотрим примеры:

(2) L'or est-il vraiment un signe ostentatoire de richesse? (Le Figaro 04/10/2017) / Является ли золото действительно признаком богатства;

(3) Fils et petit-fils de carrier, entrepreneur de marbre depuis trente-cinq ans, il a chanté l'âme des montagnes de Carrare dans un roman tendre et rugueux... Plein de poésie et d'anecdotes, La casa del colonnello est la mémoire d'une vie passée à cultiver l'or blanc, dans cette Toscane à mille lieues de Florence (Le Figaro 12/06/2017) / Сын и внук мастера, торговец каррарским мрамором на протяжении тридцати пяти лет, он воспевает душу гор Каррары в своем нежном и жестком романе... Полная стихов и анекдотов, La casa del colonnello - это память о жизни, которая прошла в добыче белого золота, в этой Тоскане, в тысяче лье от Флоренции;

(4) C'est sans doute un des rares aspects positifs de la récession économique qui frappe le Nigeria: la production de riz connaît aujourd'hui un véritable boom... «Nous vivons aujourd'hui une révolution de l'or blanc, les gens ont compris qu'on ne pouvait plus dépendre du pétrole» (Le Figaro 27/07/2017) / Это, вероятно, один из немногих положительных аспектов экономического спада в Нигерии: производство риса сегодня про- 
цветает... «Сегодня мы наблюдаем революцию белого золота, люди поняли, что они больше не могут зависеть от нефти»;

(5) Avec plus de $20 \%$ de la population mondiale, mais seulement $7 \%$ des ressources en eau, la Chine a soif d'or bleu (Novethic 12.04.2011) / Китай с $20 \%$ населения планеты, 7 \% мировых запасов воды испытывает большую потребность в голубом золоте;

(6) La Russie souhaiterait faire de ce pays un «carrefour» des routes gazières susceptible de redistribuer «l'or bleu» vers l'Europe du sud et Israël (Les Echos 04/10/2018) / Россия хотела бы сделать из этой страны «перекресток» газовых маршрутов, которая бы перераспределяла «голубое золото» в южную Европу и Израиль.

В примере (2) значение ‘золото’ объективируется благодаря ядерному компоненту 'ценный металл'. В примерах (3)-(6) ядерный компонент взаимодействует с концептом цветовой признак, что приводит к разнообразным семантическим вариантам, развивая либо омонимичность, либо полисемичность: or + blanc $\rightarrow$ marbre; or + blanc $\rightarrow$ riz; or + bleu $\rightarrow$ eau; or + bleu $\rightarrow$ gaz naturel. Но во всех вариантах сохраняется значение ценности - идет ли речь о мраморе, рисе, воде или газе. Как показывают приведенные примеры, в данном случае контекст играет определя- ющую роль, без лексического окружения представляется затруднительным определить значение полученной языковой единицы.

6. Периферийные компоненты $\rightarrow$ прагматические компоненты $\rightarrow$ ядро

В семантической структуре языковой единицы происходит взаимодействие ядерного, периферийных и прагматического компонентов. Данный процесс происходит на основе ассоциаций событийного характера, создавая новый интегративный вариант, например: guerre des devises, guerre des changes. При этом один из потенциальных компонентов становится ядерным, а ядерный компонент guerre нейтрализуется, теряет свое прямое значение 'вооруженный конфликт', где главный компонент, связанный с оружием, нейтрализуется, остается периферийный компонент 'конфликт' как способ разрешения противоречий. В новом варианте актуализируются компонент devises 'валюта' и прагматический компонент, отражающий мнение автора об эпохе финансовой глобализации. Автор этого термина американский экономист Сун Хунбин выражает в нем свое отношение к реальному устройству международных валютно-кредитных отношений, которые он характеризует как война.

Процесс внутрипо́левой интеграции может быть представлен следующей схемой (рис. 2).

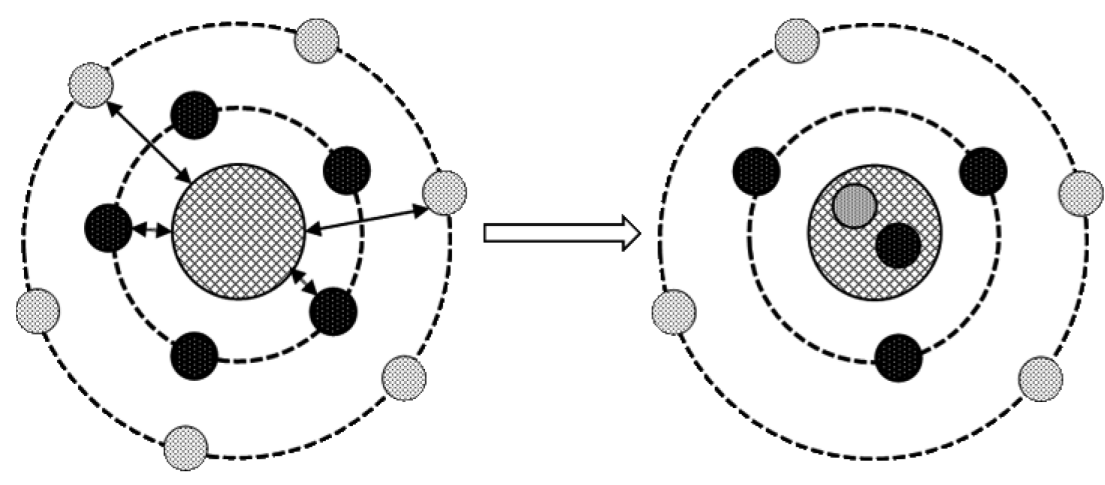

Puc. 2. Схема внутрипо́левой интеграции в языке

\section{Межпо́левая интеграция в языке}

В процессе межпо́левой интеграции формирование нового значения происходит за счет реакции внешних связей между компонентами двух или более единиц, предполагающих создание интегративного варианта и установление внутри него связей, результатом чего является изменение его ономасиологической структуры.

Специфика формирования значения интегративного варианта в данном процессе заключается в том, что актуализация и нейтрализация компонентов, объективируемых определенной морфологической структурой, зависит от типа семантических ассоци- аций между компонентами. Изменение иерархии ядерных и периферийных компонентов, попадание в фокус ядра одной единицы и нейтрализация периферийных компонентов другой единицы или наоборот создают разноструктурные интегративные варианты. «Прочтение результата» данного типа интеграции обозначает движение семантики в направлении от формы интегративного варианта к исходным компонентам, что позволяет дать его «расшифровку», а вместе с ним - и интерпретацию значения, представленного одним из своих фрагментов. Взаимное притяжение компонентов, степень их слияния в одну интегральную единицу могут быть весьма различны- 
ми и определяться разнообразными лингво-когнитивными процессами.

Рассмотрим примеры:

(7) Le bitcoin, de l'anglais bit (unité d'information binaire) et coin (pièce de monnaie), n'est pas la seule monnaie cryptographique en circulation. On peut citer l'ethereum apparu en juillet 2015 ou le zcash en octobre 2016, parmi des centaines de crypto-monnaies plus ou moins durables (Le Figaro 26/08/2017) / Биткойн, от английского bit (единица информации) и coin (монета), не является единственной криптографической валютой в обращении. Можно упомянуть эфириум, появившийся в июле 2015 г. или zcash в октябре 2016 г., являющиеся среди сотен криптовалют более или менее устойчивыми;

(8) On 1'appelle «le bollar», anagramme de dollar et bons du Trésor. Le «billet d'obligation» (ou bond note) a la couleur, la taille et la valeur du billet vert, mais ce n'est pas un dollar américain. Critiquée par l'opposition, la nouvelle devise du Zimbabwe a été présentée comme un succès (Le Figaro 08/01/2017) / Ее называют «боллар», анаграмма от dollar и bons du Trésor. Облигация имеет цвет, размер и стоимость доллара, но это не американский доллар. Новая валюта Зимбабве, критикуемая оппозицией, рекламируется как успех.

В примере (7) в термине crypto-monnaies происходит актуализация не ядра, содержащего концепт 'деньги', а периферийного компонента, проецирующего информацию об их статусе - 'виртуальные', который вербализует основной смысл данной единицы. В примере (8) интеграция ядерных компонентов двух единиц dollar и bons du Trésor формирует интегративный вариант bollar, который сохраняет значение ядра - 'деньги', но фокусирует основной смысл на оценочном выражении отношения к ним - 'недоверие', передающий мнение автора статьи, который говорит о ненадежности этой денежной единицы страны (Зимбабве), несмотря на ее внешнее сходство с американским долларом.

Процесс межпо́левой интеграции может быть представлен следующей схемой (рис. 3).
Анализ данного процесса показал, что результатом межпо́левой интеграции являются интегративные варианты, вербализованные:

1) сложными словами: vide-grenier (< vider + grenier $)$, faire-part $(<$ faire + part $)$; volatilité-obligations ( $<$ volatilité + obligations $)$; capital-risque $(<$ capital + risque); prix-chocs $(<$ prix + choc $)$; conseil-partenaire $(<$ conseil + partenaire); crédit-bail (< crédit-bail); participation-pari (< participation + pari). В их структурах обычно интегрируются имена как экономических, так и неэкономических концептов или категорий, сочетание значений компонентов создает необходимый фокус для передачи научной информации. Отношения, существующие между компонентами слова и выражающие предикацию качества, имплицитны в структуре слова;

2) композитами: crypto-monnaie (< crypto- + monnaie); cyberbanque (< cyber- + banque); e-commerce ( $<$ commerce + électronique); télémarché $(<$ télé- + marché); hyperinflation (< hyper- + inflation). Данный тип интегративного варианта характеризуется связанностью компонентов своей структуры, в которой актуализирован, как правило, компонент, находящийся в препозиции, ядерный компонент при этом сохраняется, он независим, может создавать другие варианты, в отличие от первого, особенность которого заключается в том, что при интеграции он не ассимилируется и не употребляется вне сложносоставных единиц. Характерной чертой сложных слов и композитов является то, что они представляют экономную форму номинации и выражают сложное понятие об отличительных признаках предмета (события, явления), связывая его с его классом;

3) телескопными словами: plasturgie (< métallurgie + des plastiques); actibon $(<$ charbon + activité; bollar $(<$ dollar + bons du Trésor $)$; glocalisation $(<$ globalisation + localisation); consommacteur ( $<$ consommateur + acteur); bancassurance ( $<$ banque + assurance); assurbanque (< assurer + banque). Благодаря интеграции и актуализации ядерных компонентов двух и более единиц, данный тип варианта представляет
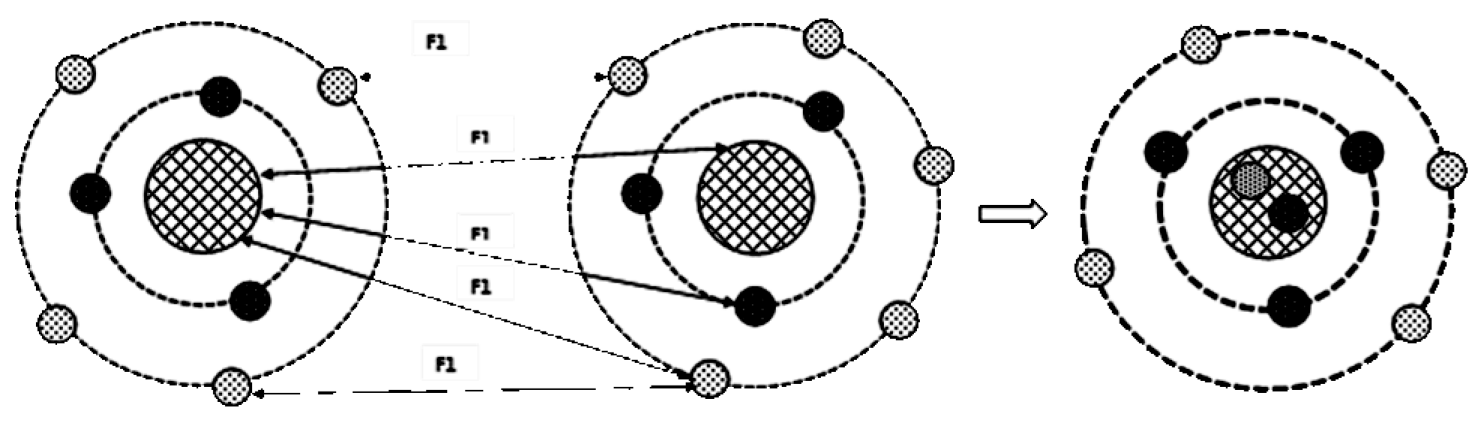

Puc. 3. Схема межпо́левой интеграции в языке 
информацию в уплотненном, конденсированном виде, что позволяет в одной единице передать бо́льший объем информации, например: mécatronique (< mécanique + électronique + informatique + automatique 'дисциплина, объединяющая механику, электронику, информатику и автоматику для поддержания систем промышленного производства'). Данная единица примечательна по объему содержания, она свидетельствует о том, что словообразовательные возможности языка неисчерпаемы;

4) устойчивыми словосочетаниями нефразеологического характера: capital fixe; affactureur à forfait; marché au comptant; valeur nette comptable, contrat bon à moyen terme négociable, système de parités fixes mais ajustables и т. д. Данный тип интегративного варианта конструируется по структурным моделям свободных синтаксических сочетаний и интегрирует различное число компонентов: от двух до семи и даже более. Поскольку степень семантического сопряжения между компонентами в данных словосочетаниях не такая высокая, ядерный компонент может употребляться или самостоятельно, или в составе других словосочетаний, например: opération $\rightarrow$ opération à découvert, opération financière, opération de comptable, opération d'échange, opération réalisable, opération de l'ajustement des taux de change и т. д.;

5) свободными терминологическими словосочетаниями, употребляющимися контекстуально. Данный тип интегративного варианта актуализирует компонент, который уточняет содержание понятия, поэтому используется только для описания специальных понятий, а не является специальной единицей, cp: mésaventure du subprime = problème des subprimes; prêt laxiste $=$ prêt hypothécaire risqué; retournement majeur de l'économie = crise économique и т. д.;

6) аббревиатурами: MATIF (Marché à terme international de France); AGETAC (Accord général sur les tarifs douaniers): $S I C A V$ (société d'investissement à capital variable; FED (Système de Réserve Fédéral), INPC (indice des prix à la consommation); TCA (taxes spéciales sur le chiffre d'affaires), $P I B$ (Produit intérieur brut) и т. д. Стремление к сжатости изложения приводит к элиминированию компонентов терминологического словосочетания, в результате чего оно выступает в сжатой, «компактной» форме. Особенностью аббревиатур является то, что они участвуют в дальнейшем словообразовании, пополняя словарный состав французского языка новыми единицами номинации. Так, от $R M I$ (revenue minimum d'insertion) 'пособие для тех, кто не получает доходов') образовалось rmiste или érémiste 'тот, кто получает это пособие'; от РМЕ образовалось PMEphilie 'préférence pour les PME'.

\section{Заключение}

Как показал анализ исследуемого материала, процессы интеграции во французском языке экономики определяются следующими факторами:

1) необходимостью в номинации появляющихся экономических реалий;

2) потребностью соответствия семантики уже имеющихся в языке единиц, их значений изменяющемуся языковому сознанию;

3) необходимостью сохранения имеющегося значения, удержания его в языковом коллективном сознании.

Данные факторы обусловливают динамичность лексико-семантической системы французского языка экономики, сохраняя определенный баланс и преемственность, благодаря чему обеспечивается эволюционное, поступательное движение развития языка.

\section{ЛИТЕРАТУРА}

1. Ирисханова О. К. О теории концептуальной интеграции // Известия АН. Серия литературы и языка. 2001. T. 60, № 3. С. 44-49.

2. Стернин И. А. Лексическое значение слова в речи. Воронеж : Издательство Воронежского университета, 1985. 137 c. URL: http://sterninia.ru/files/757/4_Izbrannye nauchnye_publikacii/Semasiologija/Leksicheskoe_znachenie_v_rechi_1985.pdf

3. Попова 3. Д., Стернин И. А. Когнитивная лингвистика. М. : АCT : Восток-Запад, 2007. 214 с. URL: file://C:/Users/User/Downloads/\%D0\%9F\% D0\%BE\%D0 $\%$ BF\%D0\%BE\%D0\%B2\%D0\%B0_\%D0\%A1\%D1\%82\% D0\%B5\%D1\%80\%D0\%BD\%D0\%B8\% D0\%BD\%20(1). pdf

4. Ирисханова О. К. Лингвокреативные основания теории номинации : дис. ... д-ра филол. наук. М., 2004. $332 \mathrm{c}$.

5. Никифорова Е. Б. Семантическая эволюция лексической системы русского языка : тенденции, векторы, механизмы : монография. Волгоград : Перемена, 2008. $326 \mathrm{c}$.

6. Micro Robert. Paris : Le Robert, 1987. C. 572.

7. Войлова K. А. Судьба просторечия в русском языке : монография. М. : Московский педагогический университет, 2000. $304 \mathrm{c}$.

8. Улуханов И. С. Словообразовательная семантика в русском языке и принципы ее описания. М. : Наука, 1977. $256 \mathrm{c}$.

\section{ИСТОЧНИКИ}

1. Le Figaro. URL: http://www.lefigaro.fr/economie

2. Le Monde. URL: http://www.lemonde.fr/economie

3. Novethic. URL: https://www.novethic.fr/

4. Les Echos. URL: https://www.lesechos.fr/economiefrance/index.php 


\section{REFERENCES}

1. Iriskhanova O. K. O teorii konceptual'noj integracii [On the theory of conceptual integration]. In: Izvestiya AN. Seriya literatury i yazyka. 2001. V. 60, No. 3. Pp. 44-49.

2. Sternin I. A. Leksicheskoe znachenie slova v rechi [The lexical meaning of the word in speech]. Voronezh: Izdatel'stvo Voronezhskogo universiteta, 1985. 137 p. Available at: http://sterninia.ru/files/757/4_Izbrannye_nauchnye publikacii/Semasiologija/Leksicheskoe_znachenie_v_rechi 1985.pdf

3. Popova Z. D., Sternin I. A. Kognitivnaya lingvistika [Cognitive linguistics]. Moscow: ACT: Vostok-Zapad, 2007. 214 p. Available at: file://C:/Users/User/Downloads/\%D0 $\% 9 \mathrm{~F} \% \mathrm{D} 0 \% \mathrm{BE} \% \mathrm{D} 0 \% \mathrm{BF} \% \mathrm{D} 0 \% \mathrm{BE} \% \mathrm{D} 0 \% \mathrm{~B} 2 \% \mathrm{D} 0 \% \mathrm{~B} 0 \%$ D0\%A $1 \%$ D $1 \% 82 \%$ D0\%B5\%D1\%80\%D0\%BD $\%$ D $0 \%$ B8\%D0\%BD\%20(1).pdf

4. Iriskhanova O. K. Lingvokreativnye osnovaniya teorii nominacii [Linguistic-creative foundations of the theory of nomination]: Dis. ... doktora filol. nauk. Moscow, 2004. $332 \mathrm{p}$.

5. Nikiforova E. B. Semanticheskaya evolyuciya leksicheskoj sistemy russkogo yazyka: tendencii, vektory,

Дипломатическая академия МИД РФ

Нечаева Н. А., дочент кафедры немецкого и франиузского языков

E-mail:dip-inyaz@yandex.ru

Поступила в редакцию 17 мая 2020 г.

Принята к публикации 25 сентября 2020 г.

\section{Для цитирования:}

Нечаева Н. А. Интеграция как фактор динамичности системы французского языка // Вестник Воронежского государственного университета. Серия: Лингвистика и межкультурная коммуникация. 2020. № 4. С. 98-106. DOI: https://doi.org/10.17308/lic.2020.4/3084 mekhanizmy: monografiya [Semantic evolution of the lexical system of the Russian language: trends, vectors, mechanisms: monograph]. Volgograd: Peremena, 2008. $326 \mathrm{p}$.

6. Micro Robert. Paris: Le Robert, 1987. P. 572.

7. Vojlova K. A. Sud'ba prostorechiya v russkom yazyke: Monografiya [The fate of vernacular in Russian: Monograph]. Moscow: Moscow Pedagogical University, 2000. 304 p.

8. Uluhanov I. S. Slovoobrazovatel'naya semantika v russkom yazyke i principy ee opisaniya [Word-formation semantics in Russian and principles of its description]. Moscow: Nauka, 1977. 256 p.

\section{SOURCES}

1. Le Monde. Available at: http://www.lemonde.fr/ economie

2. Le Figaro. Available at: http://www.lefigaro.fr/economie

3. Novethic. Available at: https://www.novethic.fr/

4. Les Echos. Available at: https://www.lesechos.fr/ economie-france/index.php

Diplomatic Academy of Ministry of Foreign Affairs of the Russian Federation

Nechaeva N. A., Associate Professor of the German and French Department

E-mail:dip-inyaz@yandex.ru

Received: 17 May 2020

Accepted: 25 September 2020

\section{For citation:}

Nechaeva N. A. Integration as a dynamic factor of the French language system. Proceedings of Voronezh State University. Series: Linguistics and Intercultural Communication. 2020. No. 4. Pp. 98-106. DOI: https://doi. org/10.17308/lic.2020.4/3084 